\title{
The Effect of Progressive Muscle Relaxation on Post Cesarean Section Pain, Quality of Sleep and Physical Activities Limitation
}

\author{
Nemat Ismail Abdel Aziz Ismail ${ }^{1} \&$ Wafaa Taha Ibrahim Elgzar ${ }^{1}$ \\ ${ }^{1}$ Obstetrics and Gynecology Nursing, Faculty of Nursing, Damanhour University, Egypt \\ Correspondence: Wafaa Taha Ibrahim Elgzar, Obstetrics and Gynecology Nursing, Faculty of Nursing, \\ Damanhour University, Egypt.
}

Received: August 5, 2018

Accepted: August 31, 2018

Online Published: September 7, 2018

doi:10.20849/ijsn.v3i3.461

URL: https://doi.org/10.20849/ijsn.v3i3.461

\begin{abstract}
Background: Pain, sleep disturbances, and physical activity limitation are the most tiresome complains of the women post caesarian section (Cs). Progressive muscle relaxation is a promising intervention for these complains. This study aimed to determine the effect of progressive muscle relaxation technique on post-cesarean section pain, quality of sleep and physical activities limitation. Research design: Randomized controlled clinical trial. Setting: post-partum unit at Damanhour National Medical Institute. Sample: A purposive sample of 80 women undergoing Cs was recruited. Randomization block was done to randomly assign 40 women for the study group and 40 for the control group. Tools: Four tools were used for data collection: structured interview schedule, short-form McGill Pain Questionnaire, Physical activities limitation Questionnaire and Groningen Sleep Quality Scale. Results: After the intervention, PMR significantly decreased pain severity among study group in Pain Rating Index scale, Visual analogue pain scale, and Present Pain Intensity scale compared to the control group. The severe physical activities limitation significantly absent from the entire study group, while it was significantly present among $70 \%$ of the control group. About two-thirds (62.5\%) of the study group had a good quality of sleep compared to 5\% of the control group. Conclusion: PMR significantly decreased pain, improved physical activities and quality of sleep among women after Cs. Recommendation: PMR should be incorporated in the nursing intervention protocols post-Cs.
\end{abstract}

Keywords: progressive muscle relaxation, pain, quality of sleep, caesarian section, physical activities limitation

\section{Introduction}

In the last few years, cesarean section (Cs) rate suddenly surge all over the world and specifically in Egypt. According to Egypt demographic and health survey 2014, Cs rate surged from 6.6\% in 1995 to $51.8 \%$ in 2014 (Ministry of Health and Population [Egypt], 2015). Although, Cs is an end for pregnancy physical and psychological problems, it is the beginning of others post Cs physical and psychological problems. Generally, woman during post-partum period is exhausted physically and psychologically, this exhaustion is doubled or even tripled in cases of Cs. However, post-partum is a critical period in which maternal and neonatal death may occur especially post Cs, it is neglected by most of the health care providers. Normally puerperal women suffer from after pain, constipation, perineal pain, urinary retention, fatigue, exhaustion, breast engorgement and postpartum blues. Furthermore, post Cs women complain from other physical and psychological problems. Physical problems include: incision pain, sleep disturbances, activity limitation, gastrointestinal disturbances, and anesthesia complications. Psychological problems include anxiety, depression, loss of control, and disturbed body image ([WHO], 2013 \& Susan et al, 2013).

Post Cs pain is complex and multifactorial. It originates from many sources. First, somatic pain results from tissue damage due to wound incision which stimulates electrical and chemical activities in the nervous system leading to pain perception in the brain. The somatic pain is well localized and often decreased or even evaporates within 2-3 days. Second, visceral pain that has two origins as abdominal organs and peritoneum manipulation during operation and uterine involution process (after pain) (Bourne et al, 2014). Visceral pain is diffuse and takes longer time than somatic pain. Uterine involution mostly completed from 10-14 days post cesarean. Third, pscho-social factors of pain. They are important factors that work behind the women perception and may stimulate the chemical neurotransmitters of pain (Chin et al, 2014). 
Post cesarean pain affects performance of daily activities and it contributes to persistent postoperative pain. The pain presented after a Cs makes the recovery difficult and delays mothers' contact with the newborns. It is also, being a hurdle to a good breastfeeding posture, newborn care, self-care, and to carry out daily activities, such as sitting down, standing up, walking, and doing personal hygiene (Borges et al, 2016 \& Pan et al 2013). The post-cesarean section pain is characterized as acute and is closely related to the damage caused to the tissue due to the inflammatory reactions derived from a traumatic operation. Even resenting a universal incident, the post-cesarean section pain is frequently ignored, which may affect the patient's satisfaction and decrease her quality of sleep (Jasim et al, 2017 \& de Sousa et al, 2009).

Disturbances in sleeping quality and quantity are universally reported among post Cs mothers. The sleep disturbances were associated with anxiety, wound pain, after pain and breastfeeding. During postpartum period the new mothers, often sacrifice their sleep to adapt to the new routines and responsibilities of breastfeeding the newborn (Creti et al, 2017 \& Ashrafinia et al, 2014). The post caesarean mother needs to tolerate more discomforts to take care of the newborn and herself. Therefore, she is subjected to more needs and problems during this transitional period. Research has shown that continuous disrupted sleep during the postpartum period may negatively affect a mother's daytime functions, breastfeeding performance, maternal satisfaction, and mother-infant interaction. Sleep disturbances post Cs are rather common and improving sleep quality has become an important research and intervention focus (Deepshikha and Vibha, 2016 \& Manjuri and Latheef, 2016).

Nursing intervention of woman post Cs is complex and need to be specifically tailored to fit to each one of the minor discomforts. But it can be concluded that management of pain, activity limitation and sleep disturbance are the most indispensable nursing interventions post Cs. If these discomforts are properly managed they will have positive impact in all the other problems. In fact, the relation between these three discomforts looks like three heads of the same triangle so, if pain was effectively managed the sleeping quantity and quality will be improved. At the same time, if pain is probably managed activity limitation will be decreased and the mother will become independent faster consequently. As pain, sleeping and activity level are related and correlated, if pain is increased sleep disturbances are also surged and activity limitation will be increased and vice versa. Although pain post Cs is distressing experience, the excessive use of analgesics is not recommended. It may result in increased risk for post-partum hemorrhage, gastrointestinal disturbances, liver impairment, renal impairment and transferred to breast milk in minimal amount (Varghese et al, 2015 \& Sutton and Carvalho, 2017). However, effective pain relive is still the highest indigence for the women post Cs. If it is not sufficiently managed it will foster more anxiety, stress, loss of control, disturbed body image, precipitate more dependency and sleep disturbances (Baird and Sheffield, 2016).

This fact necessitate that nurses should urgently search for an intervention that decrease pain, improve quality of sleep and decrease physical activity limitation. Progressive muscular relaxation is safe, effective and evidence base technique. It may help the puerperal women post Cs to have less pain, better quality of sleep and lower physical activity limitation with minimal analgesic used (Gitanjali and Sreehari, 2014).

Progressive Muscle Relaxation (PMR) is a technique used to induce a state of deep relaxation through involving systemic sequential muscle tension (for 5-7seconds) followed by relaxation (for 10-12seconds) (Sundram et al, 2016). PMR was developed by Edmund Jacobson and known in the literatures science 1938. The aim of this technique or intervention is to help the person to get mindful insight about the differences between the tension sensation and relaxation sensation in the same muscle group. This will help the woman to reach the state of deep muscle relaxation in all muscles and understand the benefits of relaxation state (Peciuliene et al, 2015 \& Jacobson, 1938). Also, during the intervention the mentor or the woman herself will instruct the woman to take deep breathing and hold it during the muscle tension state then exhale during the relaxation state. This will help to get the benefits of deep breathing exercises. Furthermore, every woman practicing this intervention should make for herself a cues or specific word to repeat to herself at the beginning of relaxation state such as "relax" or "let's go". This cues or word may help to make psychological preparation to receive relaxation sensation (Avianti et al, 2016 \& Cooke, 2013).

\subsection{Significance of the Study}

Pain, sleep disorders and physical activity limitation are the most common problem in the early post Cs period. They are routinely treated by pharmacological measure alone. Non- pharmacological methods based on sound research findings are needed to aid in post cesarean pain relief, improve quality of sleep and physical activity level (Windartik, 2017). In terms of costs and benefit, the use of non-pharmacological management is inexpensive and there are no adverse effects when compared to the use of pharmacological management. PMR 
Technique is one of the non-pharmaceutical methods used for treatment post-operative pain and sleep problems. PMR may be safe, effective, easy to learn and applicable intervention for most of the women suffers during post cesarean period. PMR technique has a hypothalamic response which decrease sympathetic arousal and decrease muscle tone. This mechanism helps to relieve pain and sleep disturbances and in turn lower physical activity limitation (Sahin and Dayapoglu, 2015 \& Ningrum et al 2017). Maternity nurses have an important role to meet the needs of women after Cs. The role of nurses is acting as an advocate and educator for women by teaching them to cope with the pain and sleep disorders, and training of PMR techniques.

\subsection{Aim of the Study}

The aim of this study was to determine the effect of PMR technique on post Cs pain, quality of sleep and physical activities limitation.

\subsection{Hypothesis}

$\mathrm{H}_{0:}$ Post Cs women who practice PMR technique have the same pain, quality of sleep and physical activities as those who do not practice it.

$\mathrm{H}_{1:}$ Post Cs women who practice PMR technique have lower pain intensity than those who do not practice it.

$\mathrm{H}_{2:}$ Post Cs women who practice PMR technique have higher quality of sleep than those who do not practice it.

$\mathrm{H}_{3:}$ Post Cs women who practice PMR technique have lower physical activities limitation than those who do not practice it.

\subsection{Operational Definition}

Progressive muscle relaxation: refers to systemic contraction of each muscle group accompanied by inhalation and holding breath for 10 seconds followed by deep relaxation of the same muscle group accompanied by slow exhalation through pursed lips within 10 seconds.

\section{Materials and Method}

\subsection{Materials}

\subsubsection{Research Design}

Randomized controlled clinical trial.

\subsubsection{Setting}

This study carried out at post-partum unit at Damanhour National Medical institute allied to ministry of health/ Elbehira governorate. This hospital is the largest governmental hospital that serves Damanhour and the surrounding areas.

\subsubsection{Sample}

A purposive sample of 80 women undergoing Cs was recruited. The women who had normal pregnancy, undergoing elective Cs with spinal anesthesia, aged 20-35 years, and accept to participate in the study were included in the study. The women who had heart disease, diabetes mellitus, pre-eclampsia or eclampsia and had complication during the operation were excluded from the study.

The sample size was estimated based on the Epi-Info 7 program using the following parameters:

(1) Target population 360 per 3 months;

(2) Expected frequency $\mathrm{p}=50 \%$;

(3) Acceptable error $=10 \%$;

(4) Confidence coefficient $=95 \%$;

(5) Sample size $=80$.

The selected women were assigned to study and control groups using randomization block technique. Randomization block her was done manually according to the following steps:

- One list contains the numbers from 1 to 80 was prepared by the researchers.

- Numbers from 1 to 80 again was written in a separate paper for each number.

- Each paper was rolled up until the number is invisible then all the papers were mixed and collected in a large ball. 
- The 80 pieces of papers were randomly and blindly divided into 4 blocks each one contains 20 random numbers.

- From each block 10 random numbers were picked up blindly to be assigned to the study group and the remaining 10 to the control group.

- Then registration of the cases sequence was done on the previously prepared list (In front of each number the researcher writes the word case or control) to be considered during data collection. A total of 40 women will be cases and 40 will be control.

\subsubsection{Tools}

Four tools were used for data collection.

\section{Tool one: structured interview schedule:}

It was developed by the researchers to collect basic data. It contains three parts. The First part included socio-demographic data such as age, level of education, occupation, current residence, and marital status. The second part concerned with history of current pregnancy such as: gestational age at delivery, and number of antenatal visits. The third part involved analgesia used as type of analgesics used and its dose per day.

\section{Tool two: The short-form McGill Pain Questionnaire:}

It was developed by Melzack1987 to assess both the quality and intensity of subjective pain. The short-form McGill Pain Questionnaire consists of three parts (Melzack, 1987).

Part I: is the Pain Rating Index (PRI) (Sensory and affective descriptors). It composed of 15 items that describe both sensory (11 items) and affective sensations (4 items) associated with pain. Each item is rated as (none $=0),($ mild=1), $($ moderate $=2)$ and $($ sever $=3)$. The total score for the 15 items ranged from 0 to 45 . The women will be considered to have:

- No pain if her total score ranged from 0 to 11

- Mild pain if her total score ranged from 12 to 23

- Moderate pain if her total score ranged from 24 to 35

- Sever pain if her total score ranged from 36 to 45

\section{Part II: Visual analogue pain scale (VAS) to assess pain intensity:}

It is a 10 points numerical scale, corresponding to the degree of pain. Where 0 indicates no pain, 1 up to 3 indicates mild pain, 4 up to 6 indicates moderate pain, 7 up to 9 indicates severe pain. Finally, 10 indicate the worst unbearable pain. The parturient was asked to select from that 10 points numerical continuum the number that corresponds to her perceived pain intensity.

Part III: Present Pain Intensity (PPI) index is based on a scale of 0-5. Where 0 indicates no pain, 1 indicates mild pain, 2 indicates discomforting, 3 indicates distressing, 4 indicates horrible, 5 indicates excruciating.

\section{Tool three Physical activities limitation Questionnaire: (PALQ)}

It was developed by the researchers to assess the limitation of physical activities due to pain after Cs. It consists of 8 items (sitting in bed, standing up, walking, performing personal hygiene, bathing, breastfeeding, eating and using a toilet) which rated as: $0=$ easy performed, $1=$ performed with difficulties, $2=$ performed with assistance, and $3=$ can't perform. The total scores ranged from 0 to 24 . The women are considered to have:

- $\quad 0-6=$ No limitation of the physical activities

- $\quad 7-12=$ Mild limitation of the physical activities

- $13-18=$ Moderate limitation of the physical activities

- $19-24=$ Severe limitation of the physical activities

\section{Tool four: The Groningen Sleep Quality Scale: (GSQS)}

It was developed by Meijman et al (1988) to measure subjective sleep quality. It is composed of 15 items of yes or no questions to evaluate the quality of sleep in the last night. The first question doesn't account from the total score. The woman gets one point if she answered yes in questions numbers 2,3,4,5,6,7,9,11,14,15 and one point if she answered no in question number 8,10,12. Scores range from 0 to 14 . A higher score on the scale means lower subjective quality of sleep (Meijman, 1988). The woman is considered to have

- Good quality of sleep if her score ranged from 0-4 
- Fair quality of sleep if her score ranged from 5-9

- Poor quality of sleep if her score ranged from 10-14

\subsection{Methods}

1. An official letter was obtained from college of nursing Damanhour University was directed to the responsible authority in Damanhour National Medical institute to gain their agreement to carry out the research after explanation of its purpose and scientific background.

2. Tool one and three were developed by the researchers after reviewing the related literatures. Tool two and four were adopted and translated into Arabic language. All tools were reviewed by a panel of four professors in the field of obstetrics and gynecology and one in the biostatistics to guarantee content validity. Then test retest was done on 8 women on 2 weeks interval to guarantee the tools reliability. Cronbach's alpha for the tool 2 , tool 3 and tool 4 were $r=0.79, r=0.84 \& \mathrm{r}=0.86$ respectively.

3. After the finalization of the tools, a pilot study was conducted on 8 women who undergoing CS to ensure clarity and applicability of the tool and estimating the time needed to complete the sheet.

4. Each woman in the study and control groups was interviewed alone in complete privacy to explain the purpose of the study, take her consent to participate, ensure her right to refuse participation or withdraw from the study at any time without any consequences. The case was considered as study or control on the base of the predetermined randomization blocks.

\section{For the study group:}

- The researchers interviewed each woman in the study group individually on the day before the operation for about 60 minutes; the researchers introduced themselves to the woman, and explained the purpose of the study, then oral consent was obtained for participation in the study. During this interview tool 1(part 1 and 2) was collected from the woman.

- The woman was asked to sit down on the bed in a comfortable position and to close her eyes and keep them closed (if possible) till the end of the technique. As for the relaxation training, the researchers demonstrated each step of PMR technique then asked the woman to re-demonstrate it, as following steps:

- Begin with a deep breathing exercise. Inhale deeply through your nose, feeling your abdomen rise as you fill your body with air. Then slowly exhale out the mouth, the navel pulling in toward the spine as you expel the stale air out. Repeat 3-5 cycles of deep breathing.

- Tense and release your muscles. Start with your feet by clenching your toes and pressing your heels toward the ground. Squeeze tightly for a few breaths and then release. Then flex your feet in, pointing your toes up towards your head, hold for 10 seconds and then, slowly release while counting for 10.

Continue to tense and then release each muscle group. Work your way up to your right leg (squeeze thigh muscles while doing above, holding for 10 seconds and then, slowly release while counting for 10) repeat on the left leg, buttocks (tensing by pulling your buttocks together, holding for 10 seconds and then, slowly release while counting for 10), abdomen(suck your abdomen in, holding for 10 seconds and then, slowly release while counting for 10), chest (tensing by taking a deep breath, holding for 10 seconds and then, slowly release while counting for 10), hands(clench your fist, holding for 10 seconds and then, slowly release while counting for 10), right arm (tighten your biceps by drawing your forearm up towards your shoulder and "make a muscle", while clenching fist, holding for 10 seconds and then, slowly release while counting for 10) repeat on the left arm, neck and shoulders (raise your shoulders up to touch your ears, holding for 10 seconds and then, slowly release while counting for 10), mouth (open your mouth wide enough to stretch the hinges of your jaw, holding for 10 seconds and then, slowly release while counting for 10), eyes (clench your eyelids tightly shut, holding for 10 seconds and then, slowly release while counting for 10), and Forehead (raise your eyebrows as far as you can, holding for 10 seconds and then, slowly release while counting for 10).

- The end your practice by taking a few deeper breaths, noting how much calmer and relaxed you feels.

- Then the researchers carried revision and reinforcement according to woman's needs. Also, the researchers corrected the wrong performance of technique and answered questions. After the 
completion of the explanation the woman was asked to re-demonstrate the relaxation technique until she can master it.

- The researchers instruct the women of the study group that technique will used four hours postoperatively after the effect of anesthesia is lost and women have conscious for 30 minutes every 8 hours throughout the day.

- Four hours post-operative, tool 1 (part3), tool 2, tool3, and tool 4 was applied as pre-test. Then the woman was instructed to demonstrate PMR technique for 30 minutes, and repeated three times per day in morning, evening and night shifts with the help and supervision of the researchers.

- After 6 sessions of PMR technique at the morning of the third day post-operative the woman's degree of pain, quality of sleep and the degree of physical activities limitation was assessed to be considered as posttest.

6. The control group: the women in the control group were left for hospital routine care. In the day before the operation the researchers interviewed each woman individually for about 15 minutes; the researchers introduced themselves to the woman and explained the purpose of the study as well as oral consent was obtained then tool 1(part 1 and 2) was collected from the woman. Then researchers interviewed the woman after the operation by four hours to apply tool 1 (part3), tool 2, tool 3, and tool 4 as pre-test. At the morning of the third day post-operative the tool 2, tool 3 and tool 4 were re-administered for the control group as post-test.

7. Data was collected over a period of five months from the beginning of January 2018 until end of May2018.

8. After data collection was completed, it was feed to SPSS to be analyzed. Data was coded and categorized, number, percentage, mean and stander deviation were used to describe the basic data. Chi-Square, Fisher Exact Test and T-test were used to test the differences between study and control groups.

\section{Results}

Table 1 shows that $77.5 \%$ of the study group and $82.5 \%$ of the control group aged 20to less than 30 years with mean age $24.300 \pm 4.165$ and $24.675 \pm 3.744$ for study and control group respectively. While nearly an equal percent (32.5\% and 35\%) of both groups have secondary education or its equivalent. The largest proportion of study $(85 \%, 92.5 \%)$ and control $(75 \%, 95 \%)$ group are housewives and married respectively. In addition, $60 \%$ and $65 \%$ of study and control group respectively are rural area residence. The mean numbers of antenatal visits

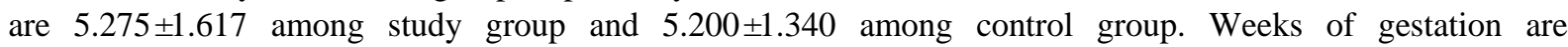
$39.350 \pm 0.770$ among study group and $39.200 \pm 0.791$ among control group. No statistically significant differences were found between both groups in relation to their socio-demographic characteristics, number of antenatal visits and weeks of gestation.

Table 2 represents that ketolac is the common analgesic used among study (85\%) and control (90) groups without significant differences between the two groups. The mean number of doses used/2days for study group is $2.800 \pm 0.564$ among study group and $5.725 \pm 0.987$ among control group with significant differences among the two groups ( $\mathrm{p}=0.001)$.

According to Table 3 PRI, it was observed that $85 \%$ of the study group had severe pain before the intervention while $2.5 \%$ of them had such pain intensity after the intervention. This is compared with $72.5 \%$ and $55 \%$ of the control group who had experienced such a severe pain before and after the intervention, respectively. The difference between the severity of pain according to the PRI scoring system among the study group before and after the intervention was statistically significant $(\mathrm{P}=0.000)$. Whereas the same difference among the control group was not statistically significant $(\mathrm{P}=0.072)$. The difference between the two groups after the intervention, in this respect was statistically significant $(\mathrm{P}=0.000)$. Concerning VAS, it was observed that $52.5 \%$ of the study group had experience worst unbearable pain before the intervention while $2.5 \%$ of them had such pain intensity after the intervention. This is compared with $37.5 \%$ and $25 \%$ of the control group who had experienced such a severe pain before and after the intervention, respectively. The difference between the severity of pain according to the VAS scoring system among the study group before and after the intervention was statistically significant $(\mathrm{P}=0.000)$. Whereas the same difference among the control group was not statistically significant $(\mathrm{P}=0.076)$. The difference between the two groups after the intervention, in this respect was statistically significant $(\mathrm{P}=0.000)$.In relation to PPI, the table shows that 55\% of the study group had experience Excruciating pain before the intervention, while none of them had such pain intensity after the intervention. This is compared with $37.5 \%$ and 
$25 \%$ of the control group who had experienced such excruciating pain before and after the intervention, respectively. The difference between the severity of pain according to the PPI scoring system among the study group before and after the intervention was statistically significant $(\mathrm{P}=0.000)$. Whereas the same difference among the control group was not statistically significant $(\mathrm{P}=0.068)$. The difference between the two groups after the intervention, in this respect was statistically significant $(\mathrm{P}=0.000)$.In conclusion, after intervention PMR significantly decreased pain severity among study group in Pain Rating Index scale, Visual analogue pain scale and Present Pain Intensity scale compared to control group.

From Table 4 it is clear that, although the PRI mean score among the study group was higher than that of the control group ( $41.300 \pm 4.177$ and $40.525 \pm 4.830$ respectively), there was no statistically significant difference between the both group, where $(\mathrm{P}=0.445)$. After intervention, the PRI mean score among the study group was lower than that of the control group $(8.375 \pm 4.453$ and $37.800 \pm 8.815$ respectively), there was highly statistically significant difference was found between the both group, where $(\mathrm{P}=0.000)$. The difference between the means of the PRI scoring system among the study group before and after the intervention was statistically significant $(\mathrm{P}=0.000)$. Whereas the same difference among the control group was not statistically significant $(\mathrm{P}=0.058)$. Concerning mean VAS, it was observed that before the intervention, although the VAS among the study group was higher than that of the control group $(9.050 \pm 1.377$ and $8.475 \pm 1.695$ respectively), there was no statistically significant difference between the both group, where $(\mathrm{P}=0.100)$. After intervention, the VAS mean score among the study group was lower than that of the control group ( $1.825 \pm 1.318$ and $7.825 \pm 2.352$ respectively), there was highly statistically significant difference was found between the both group, where $(\mathrm{P}=0.000)$. The difference between the means of the VAS scoring system among the study group before and after the intervention was statistically significant $(\mathrm{P}=0.000)$. Whereas the same difference among the control group was not statistically significant $(\mathrm{P}=0.088)$.In relation to mean PPI, the table shows that before the intervention the PPI mean score among the study group was $4.400 \pm 0.744$ compared to $4.050 \pm 0.876$ among the control group, there was no statistically significant difference between the both group, where $(\mathrm{P}=0.058)$. The difference between the means of the PPI scoring system among the study group before and after the intervention was statistically significant $(\mathrm{P}=0.000)$. Whereas the same difference among the control group was not statistically significant $(\mathrm{P}=0.996)$.

Table 5 clarify that the clear majority $(90 \% \& 90 \%)$ of the study and control groups had severe physical activities limitation before the intervention without statistically significant difference between them, where $(\mathrm{P}=0.565)$. After intervention, the severe physical activities limitation significantly absent among the entire study group, while it was significantly present among $70 \%$ of the control group where $\mathrm{P}=0.000$. The difference between the physical activities limitation scoring system among the study group before and after the intervention was statistically significant $(\mathrm{P}=0.000)$. Whereas the same difference among the control group was not statistically significant $(\mathrm{P}=0.060)$.

According to Table 6, the majority $(80 \% \& 85 \%)$ of study and control group respectively had poor quality of sleep before intervention with no statistically significant difference between them where $(\mathrm{P}=0.346)$. After the intervention, about two-thirds $(62.5 \%)$ of the study group had good quality of sleep compared to $5 \%$ of the control group. And $7.5 \%$ of study group had poor quality of sleep compared to $70 \%$ of control group, the relationship between both groups was statistically highly significant where, $(\mathrm{P}=0.000)$. The difference between the quality of sleep scoring system among the study group before and after the intervention was statistically significant $(\mathrm{P}=0.000)$. Whereas the same difference among the control group was not statistically significant $(\mathrm{P}=0.167)$.

Table 7 reveals that the study group had total mean score of quality of sleep $12.875 \pm 1.990$ compared to $13.075 \pm 1.789$ of the control group before the intervention with no statistically significant difference between them, where $(\mathrm{P}=0.638)$. on the other hand, after the intervention the study group had total mean score of quality of sleep $2.700 \pm 2.738$ compared to12.125 \pm 3.023 of the control group with statistically significant difference between them, where $(\mathrm{P}=0.000)$. The change within the study group was statistically significant, where $(\mathrm{P}=0.000)$. While the change within the control group was not statistically significant, where $(\mathrm{P}=0.000)$. 
Table 1. Number and percent distribution of the study subjects according to their socio-demographic characteristics, number of antenatal visits and weeks of gestation

\begin{tabular}{|c|c|c|c|c|c|}
\hline \multirow{2}{*}{ Variables } & \multicolumn{2}{|c|}{$\begin{array}{c}\text { Study Group } \\
(\mathbf{4 0 )}\end{array}$} & \multicolumn{2}{|c|}{ Control Group (40) } & \multirow{2}{*}{$\mathrm{F} / \chi 2(\mathrm{P})$} \\
\hline & No & $\%$ & No & $\%$ & \\
\hline Age (years): & 3 & 07.5 & 1 & 02.5 & \\
\hline $\begin{array}{l}-<20 \\
-20<30\end{array}$ & 31 & 77.5 & 33 & 82.5 & $\begin{array}{c}1.063 \\
(0.588)\end{array}$ \\
\hline$-30-35$ & 6 & 15.0 & 6 & 15.0 & \\
\hline Mean \& SD & \multicolumn{2}{|c|}{$24.300 \pm 4.165$} & \multicolumn{2}{|c|}{$24.675 \pm 3.744$} & $\begin{array}{c}0.423 \\
(0.673)\end{array}$ \\
\hline \multicolumn{6}{|l|}{ Level of education: } \\
\hline - Illiterate/read \& write & 11 & 27.5 & 8 & 20.0 & \multirow{4}{*}{$\begin{array}{c}1.733 \\
(0.630)\end{array}$} \\
\hline - Basic & 10 & 25.0 & 8 & 20.0 & \\
\hline - Secondary or its equivalent & 13 & 32.5 & 14 & 35.0 & \\
\hline - University & 6 & 15.0 & 10 & 25.0 & \\
\hline \multicolumn{5}{|l|}{ Occupation: } & \multirow{3}{*}{$\begin{array}{c}1.250 \\
(0.402)\end{array}$} \\
\hline - Housewife & 34 & 85.0 & 30 & 75.0 & \\
\hline - Working & 6 & 15.0 & 10 & 25.0 & \\
\hline \multicolumn{5}{|l|}{ Residence: } & \multirow{3}{*}{$\begin{array}{c}0.213 \\
(0.818)\end{array}$} \\
\hline - Urban & 16 & 40.0 & 14 & 35.0 & \\
\hline - Rural & 24 & 60.0 & 26 & 65.0 & \\
\hline \multicolumn{5}{|l|}{ Marital status: } & \multirow{3}{*}{$\begin{array}{c}2.347 \\
(0.309)\end{array}$} \\
\hline - Married & 37 & 92.5 & 38 & 95.0 & \\
\hline - Divorced \& widowed & 3 & 07.5 & 2 & 05.0 & \\
\hline $\begin{array}{l}\text { Number of antenatal visits: } \\
\text { Mean \& SD }\end{array}$ & \multicolumn{2}{|c|}{$5.275 \pm 1.617$} & \multicolumn{2}{|c|}{$5.200 \pm 1.340$} & $\begin{array}{c}0.222 \\
(0.825)\end{array}$ \\
\hline $\begin{array}{l}\text { Weeks of gestation: } \\
\text { Mean \& SD }\end{array}$ & \multicolumn{2}{|c|}{$39.350 \pm 0.770$} & \multicolumn{2}{|c|}{$39.200 \pm 0.791$} & $\begin{array}{c}0.860 \\
(0.393)\end{array}$ \\
\hline
\end{tabular}

$\chi^{2}(\mathrm{P}):$ Chi-Square Test $\& \mathrm{P}$ for $\chi^{2}$ TestFET $(\mathrm{P})$ : Fisher Exact Test $\&$ P for FET-Test

Table 2. Mean and percent distribution of the study subjects according to analgesia used during post cesarean period

\begin{tabular}{|c|c|c|c|c|c|}
\hline \multirow[t]{2}{*}{ Variables } & \multicolumn{2}{|c|}{$\begin{array}{c}\text { Study Group } \\
(\mathbf{4 0 )}\end{array}$} & \multicolumn{2}{|c|}{$\begin{array}{c}\text { Control Group } \\
(40)\end{array}$} & \multirow{2}{*}{$\begin{array}{l}F / \chi 2(P) T \\
\text { test }(P)\end{array}$} \\
\hline & No & $\%$ & No & $\%$ & \\
\hline $\begin{array}{l}\text { Type of analgesic used: } \\
\text { - Ketolac injection } \\
\text { - Voltarin injection }\end{array}$ & $\begin{array}{c}34 \\
6\end{array}$ & $\begin{array}{l}85.0 \\
15.0\end{array}$ & $\begin{array}{c}36 \\
4\end{array}$ & $\begin{array}{l}90.0 \\
10.0\end{array}$ & $\begin{array}{c}0.457 \\
(0.737)\end{array}$ \\
\hline $\begin{array}{c}\text { Number of doses used/2 day: } \\
\text { Mean \& SD }\end{array}$ & \multicolumn{2}{|c|}{$2.800 \pm 0.564$} & \multicolumn{2}{|c|}{$5.725 \pm 0.987$} & $\begin{array}{c}21.842 \\
(0.001) *\end{array}$ \\
\hline
\end{tabular}

$\chi^{2}(\mathrm{P})$ : Chi-Square Test $\& \mathrm{P}$ for $\chi^{2}$ TestFET $(\mathrm{P})$ : Fisher Exact Test $\&$ P for FET-Test

*: Significant at $\mathrm{P} \leq 0.05$ 
Table 3. Number and percent distribution of the study subjects according to their total scores of pain before and after the intervention

\begin{tabular}{|c|c|c|c|c|c|c|c|c|c|c|}
\hline \multirow{3}{*}{ Total Score of Pain } & \multicolumn{4}{|c|}{ Study group $=40$} & \multicolumn{4}{|c|}{ Control group $=40$} & \multirow{3}{*}{$\begin{array}{c}\text { FET } / \chi^{2}(\mathbf{P}) \\
\text { Before }\end{array}$} & \multirow{3}{*}{$\begin{array}{c}\text { FET } / \chi^{2}(\mathbf{P}) \\
\text { After }\end{array}$} \\
\hline & \multicolumn{2}{|c|}{$\begin{array}{c}\text { Before } \\
\text { intervention }\end{array}$} & \multicolumn{2}{|c|}{$\begin{array}{c}\text { After } \\
\text { intervention }\end{array}$} & \multicolumn{2}{|c|}{$\begin{array}{c}\text { Before } \\
\text { intervention }\end{array}$} & \multicolumn{2}{|c|}{$\begin{array}{c}\text { After } \\
\text { intervention }\end{array}$} & & \\
\hline & No. & $\%$ & No. & $\%$ & No. & $\%$ & No. & $\%$ & & \\
\hline \multicolumn{11}{|l|}{ Pain Rating Index (PRI): } \\
\hline - No pain ( 0 to 11$)$ & 0 & 00.0 & 20 & 50.0 & 0 & 00.0 & 3 & 07.5 & & \\
\hline - Mild pain ( 12 to 23 ) & 0 & 00.0 & 10 & 25.0 & 0 & 00.0 & 3 & 07.5 & 1.867 & 35.937 \\
\hline - Moderate pain ( 24 to 35 ) & 6 & 15.0 & 9 & 22.5 & 11 & 27.5 & 12 & 30.0 & $(0.600)$ & $(0.000) *$ \\
\hline - Sever pain ( 36 to 45$)$ & 34 & 85.0 & 1 & 02.5 & 29 & 72.5 & 22 & 55.0 & & \\
\hline $\mathbf{F E T} / \chi^{2}(\mathbf{P})$ & \multicolumn{4}{|c|}{$61.714(0.000) *$} & \multicolumn{4}{|c|}{$7.004(0.072)$} & & \\
\hline \multicolumn{11}{|l|}{ Visual analogue pain scale: } \\
\hline - No pain $=0$ & 0 & 00.0 & 7 & 17.5 & 0 & 00.0 & 0 & 00.0 & & \\
\hline - Mild pain (1 up to 3 ) & 0 & 00.0 & 21 & 52.5 & 0 & 00.0 & 7 & 17.5 & 5.746 & 28.54 \\
\hline - Moderate pain (4 up to 6) & 6 & 15.0 & 8 & 20.0 & 12 & 30.0 & 9 & 22.5 & $(0.219)$ & $(0.000) *$ \\
\hline - Severe pain (7 up to 9) & 13 & 32.5 & 3 & 07.5 & 13 & 32.5 & 14 & 35.0 & & \\
\hline - Worst unbearable pain $=10$ & 21 & 52.5 & 1 & 02.5 & 15 & 37.5 & 10 & 25.0 & & \\
\hline $\mathbf{F E T} / \chi^{2}(\mathbf{P})$ & \multicolumn{4}{|c|}{$52.718(0.000) *$} & \multicolumn{4}{|c|}{$8.466(0.076)$} & & \\
\hline \multicolumn{11}{|l|}{ Present Pain Intensity (PPI): } \\
\hline - No pain $=0$ & 0 & 00.0 & 8 & 20.0 & 0 & 00.0 & 2 & 05.0 & & \\
\hline - Mild pain=1 & 0 & 00.0 & 20 & 50.0 & 0 & 00.0 & 2 & 05.0 & 3.835 & 38.563 \\
\hline - Discomforting $=2$ & 0 & 00.0 & 8 & 20.0 & 1 & 02.5 & 7 & 17.5 & $(0.573)$ & $(0.000) *$ \\
\hline - Distressing $=3$ & 6 & 15.0 & 3 & 7.5 & 11 & 27.5 & 10 & 25.0 & & \\
\hline - Horrible $=4$ & 12 & 30.0 & 1 & 2.5 & 13 & 32.5 & 9 & 22.5 & & \\
\hline - Excruciating $=5$ & 22 & 55.0 & 0 & 00.0 & 15 & 37.5 & 10 & 25.0 & & \\
\hline $\mathbf{F E T} / \chi^{2}(\mathbf{P})$ & \multicolumn{4}{|c|}{$68.308(0.000) *$} & \multicolumn{4}{|c|}{$10.275(0.068)$} & & \\
\hline
\end{tabular}

Table 4. Pain mean scores of the study and control groups before and after the intervention

\begin{tabular}{|c|c|c|c|}
\hline Mean total score of pain & $\begin{array}{l}\text { Study Group }(n=40) \\
\text { Mean + SD }\end{array}$ & $\begin{array}{l}\text { Control Group }(n=40) \\
\text { Mean + SD }\end{array}$ & $T$ test $(P)$ \\
\hline \multicolumn{4}{|l|}{ Mean Pain Rating Index (PRI): } \\
\hline - Before intervention & $41.300 \pm 4.177$ & $40.525 \pm 4.830$ & $0.768(0.445)$ \\
\hline - After intervention & $8.375 \pm 4.453$ & $37.800 \pm 8.815$ & $18.844(0.000) *$ \\
\hline $\mathrm{T}$ test $(\mathrm{P})$ & $46.76(0.000) *$ & $1.955(0.058)$ & \\
\hline \multicolumn{4}{|l|}{ Mean Visual analogue pain scale: } \\
\hline - Before intervention & $9.050 \pm 1.377$ & $8.475 \pm 1.695$ & $1.666(0.100)$ \\
\hline - After intervention & $1.825 \pm 1.318$ & $7.825 \pm 2.352$ & $14.073(0.000) *$ \\
\hline $\mathrm{T}$ test $(\mathrm{P})$ & $34.67(0.000) *$ & $1.748(0.088)$ & \\
\hline \multicolumn{4}{|l|}{$\begin{array}{l}\text { Mean Present Pain Intensity } \\
\text { (PPI): }\end{array}$} \\
\hline - Before intervention & $4.400 \pm 0.744$ & $4.050 \pm 0.876$ & $1.926(0.058)$ \\
\hline - After intervention & $1.000 \pm 0.679$ & $3.500 \pm 1.240$ & $11.180(0.000) *$ \\
\hline $\mathrm{T}$ test $(\mathrm{P})$ & $31.67(0.000) *$ & $2.805(0.996)$ & \\
\hline
\end{tabular}


Table 5. Number and percent distribution of the study subjects according to their total scores of physical activities limitation before and after the intervention

\begin{tabular}{|c|c|c|c|c|c|c|c|c|c|c|}
\hline \multirow{3}{*}{$\begin{array}{l}\text { Total score of physical activities } \\
\text { limitation Questionnaire }\end{array}$} & \multicolumn{4}{|c|}{ Study group $=40$} & \multicolumn{4}{|c|}{ Control group $=40$} & \multirow{3}{*}{$\begin{array}{l}\text { FET } / \chi^{2}(\mathbf{P}) \\
\text { Before }\end{array}$} & \multirow{3}{*}{$\begin{array}{c}\text { FET } / \chi^{2}(\mathbf{P}) \\
\text { After }\end{array}$} \\
\hline & \multicolumn{2}{|c|}{$\begin{array}{c}\text { Before } \\
\text { intervention }\end{array}$} & \multicolumn{2}{|c|}{$\begin{array}{c}\text { After } \\
\text { intervention }\end{array}$} & \multicolumn{2}{|c|}{$\begin{array}{c}\text { Before } \\
\text { intervention }\end{array}$} & \multicolumn{2}{|c|}{$\begin{array}{c}\text { After } \\
\text { intervention }\end{array}$} & & \\
\hline & No. & $\%$ & No. & $\%$ & No. & $\%$ & No. & $\%$ & & \\
\hline - No limitation (0-6) & 0 & 00.0 & 20 & 50.0 & 0 & 00.0 & 3 & 07.5 & & \\
\hline - Mild limitation (7-12) & 1 & 02.5 & 15 & 37.5 & 0 & 00.0 & 3 & 07.5 & 1.143 & 48.656 \\
\hline - Moderate limitation (13-18) & 3 & 07.5 & 5 & 12.5 & 4 & 10.0 & 6 & 15.0 & $(0.565)$ & $(0.000) *$ \\
\hline - Severe limitation (19-24) & 36 & 90.0 & 0 & 00.0 & 36 & 90.0 & 28 & 70.0 & & \\
\hline $\mathbf{F E T} / \chi^{2}(\mathbf{P})$ & \multicolumn{4}{|c|}{$68.75(0.000) *$} & \multicolumn{4}{|c|}{$7.4(0.060)$} & & \\
\hline
\end{tabular}

$\chi^{2}(\mathrm{P}):$ Chi-Square Test $\& \mathrm{P}$ for $\chi^{2}$ TestFET (P): Fisher Exact Test $\&$ P for FET-Test

*: Significant at $\mathrm{P} \leq 0.01$

Table 6. Number and percent distribution of the study subjects according to their total Quality of Sleep score of before and after the intervention

\begin{tabular}{|c|c|c|c|c|c|c|c|c|c|c|}
\hline \multirow{3}{*}{ Total Score of Quality of Sleep } & \multicolumn{4}{|c|}{ Study group $=40$} & \multicolumn{4}{|c|}{ Control group $=40$} & \multirow{3}{*}{$\begin{array}{c}\text { FET } / \chi^{2} \\
\text { (P) } \\
\text { Before }\end{array}$} & \multirow{3}{*}{$\begin{array}{c}\text { FET } / \chi^{2} \\
(\mathbf{P}) \\
\text { After }\end{array}$} \\
\hline & \multicolumn{2}{|c|}{$\begin{array}{c}\text { Before } \\
\text { intervention }\end{array}$} & \multicolumn{2}{|c|}{$\begin{array}{c}\text { After } \\
\text { intervention }\end{array}$} & \multicolumn{2}{|c|}{$\begin{array}{c}\text { Before } \\
\text { intervention }\end{array}$} & \multicolumn{2}{|c|}{$\begin{array}{c}\text { After } \\
\text { intervention }\end{array}$} & & \\
\hline & No. & $\%$ & No. & $\%$ & No. & $\%$ & No. & $\%$ & & \\
\hline - Good quality of sleep ( 0 -4) & 0 & 00.0 & 25 & 62.5 & 0 & 00.0 & 2 & 05.0 & & \\
\hline - Fair quality of sleep (5-9) & 8 & 20.0 & 12 & 30.0 & 6 & 15.0 & 10 & 25.0 & 0.346 & 39.936 \\
\hline - Poor quality of sleep ( 10-14) & 32 & 80.0 & 3 & 07.5 & 34 & 85.0 & 28 & 70.0 & $(0.841)$ & $(0.000) *$ \\
\hline$-\quad$ FET $/ \chi^{2}(\mathbf{P})$ & \multicolumn{4}{|c|}{$49.829(0.000) *$} & \multicolumn{4}{|c|}{$3.581(0.167)$} & & \\
\hline
\end{tabular}

$\chi^{2}(\mathrm{P}):$ Chi-Square Test $\& \mathrm{P}$ for $\chi^{2}$ TestFET $(\mathrm{P})$ : Fisher Exact Test $\&$ P for FET-Test

$*$ : Significant at $\mathrm{P} \leq 0.01$

Table 7. Quality of sleep mean scores of the study and control groups before and after the intervention

\begin{tabular}{llll}
\hline $\begin{array}{l}\text { Mean total Score of Quality } \\
\text { of Sleep }\end{array}$ & $\begin{array}{c}\text { Study Group }(\mathbf{n}=\mathbf{4 0}) \\
\text { Mean }+ \text { SD }\end{array}$ & $\begin{array}{c}\text { Control Group }(\mathbf{n}=\mathbf{4 0}) \\
\text { Mean }+ \text { SD }\end{array}$ & T test $(\mathbf{P})$ \\
\hline Before intervention & $12.875 \pm 1.990$ & $13.075 \pm 1.789$ & $0.473(0.638)$ \\
After intervention & $2.700 \pm 2.738$ & $12.125 \pm 3.023$ & $14.615(0.000) *$ \\
T test $(\mathbf{P})$ & $23.5(0.000) *$ & $1.988(0.054)$ & \\
\hline
\end{tabular}

$\mathrm{T}(\mathrm{P})$ : T-test $\& \mathrm{P}$ for T-test*: Significant at $\mathrm{P} \leq 0.01$

\section{Discussion}

In fact, the rate of CS is incredibly increased worldwide. This surge in the rate of CS necessity the finding of effective and safe measures that can help the women to reassume her ordinary life rapidly. This can be achieved by relieving post Cs pain and consequently improve activity level and sleeping. PMR is assumed to be an effective and safe technique for that purpose.

In the present study it was observed that PMR significantly decreased pain severity among study group after intervention compared to control group. The result of the present study is in line with at least six studies. First, Devmurari and Nagrale (2018) who studied "Effectiveness of Jacobson's PMR technique for pain management in post-cesarean women". They found that $100 \%$ of experimental group after intervention had pain ranging from 0 to 5 compared to $17.6 \%$ of control group. There is significant difference in mean values between pain scores of control and experimental group on VAS score. They further concluded that the pain is more reduced in experimental than control group. Second, Devi et al (2017) who studied " Effect of PMR on post-operative analgesia" among patients with abdominal surgery in India during the first two days post-operative. They reported that PMR was very effective in pain relieve among study group compared to control group. They further added that PMR helped their patients to overcome the distressing feelings during post-operative period and improve their quality of life. Third, Akınc1 et al (2016) who studied " The effects of posture and relaxation training on sleep, 
dyspnea, pain and, quality of life in the short-term after cardiac surgery". They concluded that pain significantly decreased among study group during and after intervention while it remains steady among control group. Fourth, Gupta et al (2016) who studied "Effectiveness of PMR technique on physical symptoms among patients receiving chemotherapy". They elaborated that around two thirds (63.3\%) among their study participant had only mild pain post intervention compared to non-before it. They further added that none of their study group complained from severe pain post intervention compared to $100 \%$ before intervention. Fifth, Solehati et al (2015) who studied "Benson relaxation technique in reducing pain intensity in women after Cs". They reported that Benson relaxation technique significantly decreased pain after Cs compared with before intervention and control group. In their study Benson relaxation technique refers to a state of deep relaxation with concentration on the sense of relaxation by repeating a key word convey the sense of relaxation. This technique is also accompanied with deep breathing exercises. Sixth, Paula et al (2002) who studied "the use of PMR technique for pain relief in gynecology and obstetrics". Their subjects were patients with abdominal surgery for obstetrics or gynecologic reason. They concluded that PMR significantly decreased pain perception among study group compared to control group. They further recommended that health care team should prepare their patients to apply PMR during the preoperative period to be used as a pain control method during the post-operative period.

In conclusion a very recent meta-analysis conducted by Wang et al (2018) about "Perioperative psychotherapy for persistent postsurgical pain and physical impairment" reported similar result with the current study. They reviewed 11757 studies and concluded that moderate quality evidences supported the hypothesis that perioperative psychotherapy including PMR significantly decreased pain during post-operative period.

The result of the current study is also in line with relevant literatures. PMR may work to decrease post Cs pain through numerous mechanisms. First, PMR is effective in decreasing stress and consequently stress hormones (cortisol, epinephrine, catecholamines). Second, it can inhibit sympathetic and stimulate the parasympathetic nerves by blocking the feedback pathway from the mind to muscles and consequently prevent the biological response to pain. So, it may lower blood pressure, heart rate and metabolic rate (Avianti et al, 2016 \& Topcu and Findik, 2012). Third, PMR may manipulate the hypothalamus by concentration on the positive sensation of deep relaxation state during the intervention so, the stress impulses from the hypothalamus is decreased or even inhibited. Fourth the deep breathing technique during the intervention can increase oxygen saturation, decrease the oxidative factors and consequently, pain. Fifth, PMR may help the secretion of endogenous endorphins, decrease the secretion of adrenal hormones, and improve blood circulation (Peciuliene et al 2015).

In the present study, most of the study and control groups had severe physical activities limitation before the intervention without statistically significant difference between them. After intervention, the severe physical activities limitation significantly absent among the entire study group, while it was significantly present among $70 \%$ of the control group. This result is in congruence with Dhyani et al (2015) who conducted a study about "effect of PMR on stress and disability in subjects with chronic low back pain". They concluded that PMR significantly reduced disability behaviors and functions related to pain. In addition, Berge et al (2004) studied "pre-operative and post-operative effect of pain management program prior to total hip replacement". They elaborated inside their article that the pain management program mainly depending on systemic regular tonic and relaxation of muscle groups. They elaborated that study group activity score was significantly higher than control group. Although the use of analgesics did not differ between the two groups. Furthermore, cheung et al (2003) studied "the effect of progressive muscle training on anxiety and quality of life after stoma surgery in colorectal cancer patients". They reported that the use of PMR significantly improve the quality of life among study group compared to control group especially in the domain of physical health.

The results of the current study seem to be logic because according to Borges et al (2016) the most common predicator for pain after Cs is activity restriction. Mostly, if the woman in pain she will avoid movement to control pain. So, if PMR can help in pain relive consequently activity will be improved and the opposite is also correct. In addition, Sousa et al (2009) made in depth studying of the relationship between the degree of post cesarean pain and its relation to the limitation of physical activities. They concluded that $100 \%$ of their participants reported restriction in sitting down, standing up and walking due to pain post Cs.

The effects of the PMR on quality of sleeping in post cesarean mothers have not yet been investigated. However, many studies carried out in different population such as (pregnant women, cancer patients, patients with joints replacement surgery, patients with pulmonary resection, pulmonary disease patients, Hemodialysis patients, and patients with cardiac surgery) have proved PMR to be effective in improvement of quality of sleeping.

The present study revealed that after the intervention, about two-thirds $(62.5 \%)$ of the study group had good quality of sleep compared to $5 \%$ of the control group, with statistically significant difference between them, 
where $(\mathrm{P}=0.000)$.this result indicated that significantly higher improvement in quality of sleeping among study group than the control group. This result suggests a possible positive effect of PMR technique on improvement of quality of sleeping among women after CS. This finding may be attributed to the fact that PMR may enhance sleep quality by relaxing the body, decreasing the blood pressure, stimulating circulation, and ensuring muscle relaxation. These exercises facilitate transition to parasympathetic nervous system, and as a result, ensure physical and mental relaxation (Roozbahani et al 2016).

A similar result was observed in Aksu et al (2017) research. They had investigated "effects of PMR training on sleep and quality of life in patients with pulmonary resection". They found that the patients in the treatment group showed significantly greater post-treatment improvement than the control group in terms of the total PSQI score, subjective sleep quality, sleep latency, sleep duration, sleep efficiency, sleep disturbance, and daytime functions, $(\mathrm{p}<0.05)$. Another study conducted by Masry et al (2017) who had evaluated "effect of Benson's relaxation technique on night pain and sleep quality among adults and elderly patients undergoing joints replacement surgery". They found an improvement in sleep quality scores among study group than control group after implementing Benson relaxation technique at one day postoperative and 3rd postoperative day. In addition, the same result is also congruent with Kumar and Bhardwaj (2017) who had evaluated "the effectiveness of PMR inducing sleep among cancer patients". They found that the average post-test score of the participants is significantly low than average pre- test score in terms of effect of PMR technique on inducing sleep. Hence the PMR technique on inducing sleep among Cancer patients is significantly effective. Furthermore, this finding is also in agreement with the results of another study done by Yilmaz and Kapucu (2017) who studied the "effect of progressive relaxation exercises on fatigue and sleep quality in Individuals with COPD". They reported that the patients with COPD who used PMR were seen to experience fewer sleep problems in their study. They concluded that PMR was found to be effective in decreasing dyspnea, fatigue, and sleep problems in their study. Furthermore, Yousefi and Taraghi (2017) who conducted systemic review about progressive muscle relaxation and sleep quality. They concluded that in all articles, PMR has been able to reduce the global score of patients' sleep quality but hasn't been able to reach sleep quality at a normal range (PSQI $<5)$. In addition, in some studies, only a few components of the sleep quality were improved.

The same result is also congruent with the results of at least five other researches. First, Akınc1 et al (2016) who found that posture and relaxation training have beneficial effects for maintaining sleep quality, and reducing sleep medication use, in cardiac surgery patients. In conclusion, the results of their study showed that PMR has a preventive effect on sleep disturbances and reduces the need for sleep medication after cardiac surgeries. Second, Amini et al (2016) who studied "effect of PMR and aerobic exercise on anxiety, sleep quality, and fatigue in patients with chronic renal failure undergoing hemodialysis". They reported that the mean score for sleep quality decreased significantly after the intervention in the PMR group, which represents the significant improvement of sleep quality. Third, Rashed et al (2016) who studied " effect of non-pharmacological interventions on sleep quality during pregnancy among primigravida". They reported that there was a statistically significant difference between groups after the intervention regarding score of sleep quality index. The progressive relaxation group's participants tend to have a high-quality sleep after the intervention indicated by having the lowest PSQI score and the highest amount of score change as compared to other both groups. Fourth, Karbandi et al (2015) who had conducted a study titled "recognition of the efficacy of relaxation program on sleep quality of mothers with premature infants". They concluded that Relaxation training can improve maternal postpartum sleep quality and considering the advantages of relaxation and low cost to learn and use it. Fifth, Golmakani et al (2015) who had compared "the effects of PMR and guided imagery on sleep quality in primigravida women". They concluded that PMR positively affected the sleep quality of primigravida women.

On the other hand, the current study result contradicts to the findings of Chegeni et al (2018) who had conducted a study titled "the effect of PMR on the management of fatigue and quality of sleep in patients with chronic obstructive pulmonary disease". They reported that no significant difference between the groups in terms of mean score of global sleep quality, and the between-group analysis of sleep quality subscales also showed no significant differences between the two groups in mean scores of subjective sleep quality, sleep latency, sleep duration, and habitual sleep efficiency. They concluded that no effect on global sleep quality and its subscales of sleep disturbances, use of sleeping medications, and daytime dysfunction.

This difference between the present study and the later one may be related to the difference in the nature of diseases where the current study deals with post Cs woman without complications or chronic diseases where Chegeni et al (2018) deals with COPD patient whose disease is aggravated by lying down. Furthermore, muscle contractions during PMR technique may consume more oxygen and precipitate orthopnea. Another factors that may contribute to the difference between the current study and Chegeni et al (2018) one are design of 
intervention, duration and frequency of relaxation, number of training session, tools used to measure sleep quality, number of samples, gender of samples and inclusion and exclusion criteria.

\section{Conclusion}

Based on the results of current study, it was concluded that post cesarean women who practice progressive muscle relaxation technique have lower post cesarean pain, higher quality of sleep and lower physical activities limitation than those who received only the routine nursing care.

\section{Recommendations}

Based on the findings of the current study, the following recommendations can be suggested:

- PMR is a practice that is inexpensive, effective, and easy to apply during the hospitalization period. Therefore, the nursing team should involve such practices in nursing management after Cs.

- The curriculum of basic nursing / midwifery education as well as continuing education should entail the PMR technique for management of pain and improve quality of sleeping after Cs.

- Patient's education about PMR technique should be implemented with all post cesarean women to help relieve pain and enhance sleep quality.

- Future researches:

a) Replication of the study using a large probability sample from a broad geographical area to allow greater generalization of the results.

b) Exploration of the effect of PMR on stress, fatigue, and quality of life during postpartum.

\section{References}

Akıncı, B., Yeldan, I., Bayramoğlu, Z., \& Akpınar, T. (2016). The effects of posture and relaxation training on sleep, dyspnea, pain and, quality of life in the short-term after cardiac surgery: a pilot study. Turk Gogus Kalp Dama, 24(2), 258-265. https://doi.org/10.5606/tgkdc.dergisi.2016.11675

Aksu, N., Erdogan, A., \& Ozgur, N. (2017). Effects of progressive muscle relaxation training on sleep and quality of life in patients with pulmonary resection. Sleep Breathing Physiology and Disorders, 6(3), 1-8. https://doi.org/10.1007/s11325-017-1614-2

Amini, E., Goudarzi, I., Masoudi, R., Ahmadi, A., \& Momeni, A. (2016). Effect of Progressive Muscle Relaxation and Aerobic Exercise on Anxiety, Sleep Quality, and Fatigue in Patients with Chronic Renal Failure Undergoing Hemodialysis. International Journal of Pharmaceutical and Clinical Research, 8(12), 1634-1639.

Ashrafinia F., Mirmohammadali, M., Rajabi, H., Kazemnejad, A., Sadeghniiat Haghighi, K., Amelvalizadeh, M., \& Chen, H. (2014). The effects of Pilates exercise on sleep quality in postpartum women. J. Bodyw. Mov. Ther., 18(2), 190-199. https://doi.org/10.1016/j.jbmt.2013.09.007

Avianti, N., Desmaniarti, Z., \& Rumahorbo, H. (2016). Progressive Muscle Relaxation Effectiveness of the Blood Sugar Patients with Type 2 Diabetes. Open Journal of Nursing, 6(3), 248-254. https://doi.org/10.4236/ojn.2016.63025

Baird, A., \& Sheffield, D. (2016). The Relationship between Pain Beliefs and Physical and Mental Health Outcome Measures in Chronic Low Back Pain: Direct and Indirect Effects. Journal of Healthcare, 4(3), 58-68. https://doi.org/10.3390/healthcare4030058

Berge, D., Dolin, S., Williams, A., \& Harman, R. (2004). Pre-operative and post-operative effect of a pain management programme prior to total hip replacement: a randomized controlled trial. Pain, 110, 33-39. https://doi.org/10.1016/j.pain.2004.03.002

Borges, N., Pereira, L., de Moura, L., Silva, T., \& Pedroso, C. (2016). Predictors for Moderate to Severe Acute Postoperative Pain after Cesarean Section. Pain Research and Management. Hindawi Publishing Corporation, 2016, 6.

Bourne, S., Machado, G., \& Nagel, J. (2014). Basic anatomy and physiology of pain pathways. NeurosurgClin N Am., 25, 629-638. https://doi.org/10.1016/j.nec.2014.06.001

Chegeni, P., Gholami, M., Azargoon, A., Pour, A., Birjandi, M., \& Norollahi, H. (2018). The effect of progressive muscle relaxation on the management of fatigue and quality of sleep in patients with chronic 
obstructive pulmonary disease: A randomized controlled clinical trial. Complementary Therapies in Clinical Practice, 31, 64-70. https://doi.org/10.1016/j.ctcp.2018.01.010

Cheung, Y., Molassiotis, A., \& Chang, A. (2003). The effect of progressive muscle relaxation training on anxiety and quality of life after stoma surgery in colorectal cancer patients. Psycho-Oncology, 12(3), 254-266. https://doi.org/10.1002/pon.638

Chin, E., Vincent, C., \& Wilkie, D. (2014). A comprehensive description of postpartum pain after cesarean delivery. Journal of Obstetric, Gynecologic \& Neonatal Nursing, 43(6), 729-741. https://doi.org/10.1111/1552-6909.12483

Cooke, H. (2013). Progressive Muscle Relaxation. CAM-Cancer J., 1(1), 1-6.

Creti, L., Libman, E., Rizzo, D., Fichten, C., Bailes, S., Tran, D., \& Zelkowitz, P. (2017). Sleep in the Postpartum: Characteristics of First-Time, Healthy Mothers. Sleep Disorders, 2017, 10. https://doi.org/10.1155/2017/8520358

De Sousa, L., Pitangui, A., Gomes, F., Nakano, A., \& Ferreira, C. (2009). Measurement and characteristics of post-cesarean section pain and the relationship to limitation of physical activities. Acta Paul Enferm, 22(6), 741-747.

Deepshikha, A., \& Vibha, H. (2016). Effect of Foot Reflexology on Post Operative Pain and Sleep among Post Caesarean Mothers. Int. J. Nur. Edu. and Research, 4(4), 441-444. https://doi.org/10.5958/2454-2660.2016.00081.8

Devi, R., \& Saharia, K. (2017). Effect of progressive muscle relaxation on post-operative analgesia. Int J Med Res Rev, 5(2), 113-118. https://doi.org/10.17511/ijmrr

Devmurari, D., \& Nagrale, S. (2018, April-June). Effectiveness of Jacobson's progressive muscle relaxation technique for pain management in post-cesarean women. Indian Journal of Obstetrics and Gynecology Research, 5(2), 228-232. https://doi.org/10.18231/2394-2754.2018.0051

Dhyani, D., Sen, S., \& Raghumahanti, R. (2015). Effect of Progressive Muscular Relaxation on Stress and Disability in Subjects with Chronic Low Back Pain. IOSR Journal of Nursing and Health Science, 4(1), 40-45.

Gitanjali, N., \& Sreehari, R. (2014). Progressive Muscular Relaxation as a Multi-pronged psychotherapeutic technique for Insomnia. Amrita Journal of Medicine, 10(1), 33-35.

Golmakani, N., Nejad, F., Shakeri, M., \& Pour, N. (2015). Comparing the Effects of Progressive Muscle Relaxation and Guided Imagery on Sleep Quality in Primigravida Women Referring to Mashhad Health Care Centers-1393. Journal of Midwifery and Reproductive Health, 3(2), 335-342.

Gupta, B., Kumari, M., \& Kaur, T. (2016). Effectiveness of progressive muscle relaxation technique on physical symptoms among patients receiving chemotherapy. Nursing and Midwifery Research Journal, 12(1), 33-40.

Jacobson, E. (1938). Progressive Relaxation (2nd ed.). University of Chicago Press, Chicago.

Jasim, H., Sulaiman, S., Khan, A., \& Rajah, U. (2017). Post Caesarean Pain Intensity among Women in a Hospital in the Northern Peninsular of Malaysia. Journal of Clinical and Diagnostic Research, 11(9), IC07-IC11.

Karbandi, S., Hosseini, S., Masoudi, R., Hosseini, S., Sadeghi, F., \& Moghaddam, M. (2015). Recognition of the efficacy of relaxation program on sleep quality of mothers with premature infants. Journal of Education and Health Promotion, 4, 97-102.

Kumar, B., \& Bhardwaj, G. (2017). Effectiveness of Progressive Muscle Relaxation on Inducing Sleep among Cancer Patients in Selected Hospitals of Pune City. International Journal of Science and Healthcare Research, 2(3), 35-40.

Manjuri, A., \& Latheef, F. (2016). Effectiveness of foot reflexology and back massage in improving the quality of sleep among post caesarean mothers. International journal of research in Ayurveda pharmacy, 7(5), 103-108. https://doi.org/10.7897/2277-4343.075204

Masry, S., Aldoushy, E., \& Ahmed, N. (2017). Effect of Benson's Relaxation Technique on Night Pain and Sleep Quality among Adults and Elderly Patients Undergoing Joints Replacement Surgery. International Journal of Nursing Di dactics, 7(4), 1-8. 
Meijman, T.F., de Vries-Griever, A.H., \& de Vries, G. (1988). The evaluation of the Groningen Sleep Quality Scale. Groningen: Heymans Bulletin (HB 88-3-EX).

Melzack, R. (1987). The short-form McGill pain questionnaire. Science Direct Journals, 30(2), 191-197. https://doi.org/10.1016/0304-3959(87)91074-8

Ministry of Health and Population [Egypt], El-Zanat y and Associates [Egypt], and ICF International. (2014). Egypt Demographic and Health Survey. Cairo, Egypt and Rockville, Maryland, USA: Ministry of Health and Population and ICF International.

Ningrum, N., Mahdiyah, D., \& Sari, D. (2017). Effectiveness of Relaxation Techniques to Decrease Handheld Finger Pain Intensity Post Cesarean Section at Dr. H. Moch. Ansari Saleh Hospital in Banjarmasin. Advances in Health Science Research, 6, 188-195. https://doi.org/10.2991/smichs-17.2017.23

Pan, P., Tonidandel, A., Aschenbrenner, C., Houle, T., Harris, L., \& Eisenach, J. (2013). Predicting acute pain after cesarean delivery using three simple questions. Anesthesiology, 118(5), 1170-1179. https://doi.org/10.1097/ALN.0b013e31828e156f

Paula, A., Carvalho, E., \& Santos, C. (2002). The use of the progressive muscle relaxation technique for pain relief in gynecology and obstetrics. Rev Lat Am Enfermagem, 10(5), 654-659. https://doi.org/10.1590/S0104-11692002000500005

Peciuliene, L., Perminas, A., Gustainiene, L., \& Jarasiunaite, G. (2015). Effectiveness of Progressive Muscle Relaxation and Biofeedback Relaxation in Lowering Physiological Arousal among Students with Regard to Personality Features. Procedia-Social and Behavioral Sciences, 2015(205), 228-235. https://doi.org/10.1016/j.sbspro.2015.09.064

Rashed, A., Khalil, A., \& Abo Shereda, H. (2016). Effect of Non-Pharmacological Interventions on Sleep Quality during Pregnancy among Primigravida. IOSR Journal of Nursing and Health Science, 5(6), 7-15.

Roozbahani, T., Nourian, M., Saatchi, K., \& Moslemi, A. (2016). Effects of Progressive Muscle Relaxation on Sleep Quality in Pre-university Students: A Randomized Clinical Trial. Scientific Journal of Hamadan Nursing \& Midwifery Faculty, 24(1), 16-23. https://doi.org/10.20286/nmj-24013

Sahin, Z., \& Dayapoglu, N. (2015). Effect of progressive relaxation exercises on fatigue and sleep quality in patients with chronic obstructive lung disease (COPD). Complementary Therapies in Clinical Practice, 21, 277-281. https://doi.org/10.1016/j.ctcp.2015.10.002

Solehati, T., \& Rustina, Y. (2015). Benson Relaxation Technique in Reducing Pain Intensity in Women After Cesarean Section. Anesthesiology and Pain Medicine, 5(3), e22236. https://doi.org/10.5812/aapm.22236v2

Sousa, L., Pitangui, A., Gomes, F., Nakano, A., \& Ferreira, C. (2009). Measurement and characteristics of post-cesarean section pain and the relationship to limitation of physical activities. Acta Paul Enferm, 22(6), 741-747. https://doi.org/10.1590/S0103-21002009000600003

Sundram, B., Dahlui, M., \& Chinna, K. (2016). Effectiveness of progressive muscle relaxation therapy as a worksite health promotion program in the automobile assembly line. National Institute of Occupational Safety and Health, 54(3), 204-214. https://doi.org/10.2486/indhealth.2014-0091

Susan, M., Knapp, H., Borucki, L., Roncoli, M., Arnold, L., \& Brooten, D. (2013). Major Concerns of Women After Cesarean Delivery. Journal Gynecology and Neonatal Nursing, (1), 53-59.

Sutton, C., \& Carvalho, B. (2017, December). Optimal Pain Management After Cesarean Delivery. Anesthesiology Clinics, 35(1), 107-124. https://doi.org/10.1016/j.anclin.2016.09.010

Topcu, S., \& Findik, U. (2012). Effect of relaxation exercises on controlling postoperative pain. Pain Manag Nurs., 13(1), 11-17. https://doi.org/10.1016/j.pmn.2010.07.006

Varghese, J., George, J., \& Gowda, Y. (2015). A Randomized Control Trial to Determine the Effect of Foot Reflexology on Intensity of Pain and Quality of Sleep in Post Caesarean Mothers. IOSR Journal of Nursing and Health Science, 3(1), 39-43. https://doi.org/10.9790/1959-03143943

Wang, L., Chang, Y., Kennedy, S., Hong, P., Chow, N., Couban, R., ... Busse, J. (2018). Perioperative psychotherapy for persistent postsurgical pain and physical impairment: a meta analysis of randomized trials. British Journal of Anaesthesia, 120(6), 1304-1314. 
Windartik, E., Yuniarti, E., \& Akbar, A. (2017). Effectiveness of Relaxation Handheld Finger technique and Benson Relaxation to the Changes Level of Post Operative Pain cesarean section in Rsi Sakinag Mojokerto. International Journal of Scientific Research and Management (IJSRM), 5(9), 7107-7111.

World health organization. (2013). WHO recommendations on Postnatal care of the mother and newborn.

Yilmaz, C., \& Kapucu, S. (2017). The Effect of Progressive Relaxation Exercises on Fatigue and Sleep Quality in Individuals with COPD. Holistic Nursing Practice, 31(6), 369-377. https://doi.org/10.1097/HNP.0000000000000234

Yousefi, S., \& Taraghi, Z. (2017). Progressive muscle relaxation and sleep quality: a literature review. Pharmacophore, 8(1), 19-24.

\section{Copyrights}

Copyright for this article is retained by the author(s), with first publication rights granted to the journal.

This is an open-access article distributed under the terms and conditions of the Creative Commons Attribution license (http://creativecommons.org/licenses/by/4.0/). 